\title{
Economic valuation of Shadegan International Wetland, Iran: notes for conservation
}

\begin{abstract}
Wetlands are among the most productive ecosystems on the earth. They produce various market and non-market goods and services, which have a significant role in human welfare. Despite the great opportunities from sustainable development, wetlands all over the world are under serious threat from a diverse range of non-sustainable activities. One of the major reasons for excessive depletion and the conversion of wetland resources is due to underestimating the non-market values of wetlands during development decisions. Shadegan International Wetland (SIW) in southern Iran is one of these wetland areas that is threatened by undervaluation and overexploitation from commercial activities. This study utilizes the contingent valuation method to estimate the economic benefits of SIW from the view point of peoples' willingness to pay (WTP). The logit model was defined based on dichotomous choice to measure individuals' WTP. The estimated mean WTP was US\$ 1.74 per household as a onetime donation. This study concludes that the benefits of SIW to society could encourage managers to set priorities to ensure that the health of the ecosystem, its integrity, and its uniqueness would be conserved in a proper manner.
\end{abstract}

Keyword: Shadegan International Wetland; Non-market value; Contingent valuation; Willingness to pay; Logit model 